\title{
Interfaces das interfaces socioestatais: ouvidorias, conselhos gestores e Facebooks governamentais
}

Artigos Originais

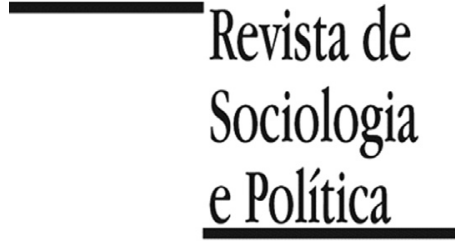

DOI 10.1590/1678-987320287405

\author{
Lígia Helena Hahn Lüchmann' \\ IDepartamento de Sociologia e Ciência Política, Universidade Federal de Santa Catarina, Florianópolis, SC, Brasil.
}

RESUMO Introdução: $O$ trabalho visa analisar a ocorrência de articulações entre três diferentes modalidades de interfaces entre Estado e sociedade: ouvidorias, conselhos gestores e Facebooks governamentais. Materiais e Métodos: O estudo privilegiou o mapeamento dessas interfaces em três diferentes áreas de políticas públicas: saúde, assistência social e meio ambiente e em dois níveis de governo (Governo do Estado de Santa Catarina e Prefeitura Municipal de Florianópolis). A partir de um mapeamento geral das interfaces identificadas nas respectivas páginas das Secretarias de Governo, a pesquisa contou com a análise de documentos, realização de entrevistas, levantamento de registros em Atas de conselhos e postagens nos Facebooks governamentais. Resultados: Tomando como base analítica dimensões como atribuições, competências, desenho institucional, área de políticas públicas e atuação de atores políticos, burocráticos e sociais, a pesquisa identificou diferenças importantes na maior ou menor capacidade de diálogo e interlocução entre as três modalidades de interface socioestatal, com destaque positivo para os conselhos nas áreas da saúde e assistência social. Discussão: A pesquisa apresenta um avanço nos estudos sobre as interfaces socioestatais, alargando, para além das instituições participativas, as modalidades de participação da sociedade junto às agências governamentais. Apesar do escopo limitado do estudo, em especial quando se considera a complexidade e a variedade de programas e dispositivos participativos no âmbito das agências e estruturas governamentais e as especificidades locais e regionais, o artigo reforça a importância de se ampliar, de forma relacional, o entendimento desse fenômeno.

PALAVRAS-CHAVE: interfaces socioestatais; instituições participativas; governança; conselhos gestores; Facebooks governamentais.

Recebido em 27 de Maio de 2019. Aprovado em 27 de Fevereiro de 2020. Aceito em 14 de Maio de 2020.

\section{Introdução ${ }^{1}$}

${ }^{1}$ Este trabalho é resultado da pesquisa $\mathrm{PQ} / \mathrm{CNPq}$ intitulada "Interfaces socioestatais: da participação à burocracia estatal".

\footnotetext{
2 Além da extinção de conferências de políticas públicas, uma das primeiras medidas do governo conservador que venceu as eleições de 2018 foi a edição do Decreto 9.759/abril de 2019, visando extinguir vários conselhos de Políticas Públicas do país.
}

$\mathrm{N}$ o campo de estudos sobre participação e teoria democrática, o Brasil tornou-se referência de inovação democrática (Smith, 2019) por ter criado políticas participativas inovadoras, a exemplo do orçamento participativo (OP), internacionalmente reconhecido. Trilhando caminhos próprios, diferentes países do mundo adotaram programas de OP, além de ampliarem significativamente outras modalidades participativas, muitas delas em formato digital. No Brasil, modalidades presenciais e digitais de participação também foram se multiplicando no âmbito das instituições governamentais. Em que pese o contexto atual de desmonte da participação institucional no país ${ }^{2}$, o fato é que, no decorrer das últimas décadas, diversas instituições participativas (IP), como os conselhos gestores e as conferências de políticas públicas, se expandiram para muitas áreas de políticas públicas nas três esferas de governo - municipal, estadual e nacional -, alcançando mais de 30 mil conselhos em âmbito municipal e mais de 100 conferências nacionais, na década de 2010. Testemunhamos também a expansão das ouvidorias, das audiências e consultas públicas, e de ferramentas digitais, a exemplo dos Facebooks governamentais.

Essas diferentes modalidades de interfaces socioestatais, e que promovem algum tipo de aproximação e de diálogo entre cidadãs e cidadãos com atores e setores governamentais, desenham um quadro de pluralização da participação 
institucional no país que desafia as abordagens no campo dos debates sobre teoria democrática e governança, em especial pela crescente criação de instrumentos de participação não presenciais que, se por um lado potencializam a expressão de novas vozes sociais, também ecoam novos ruídos na capacidade de escuta, diálogo e coordenação entre diferentes espaços, mecanismos e instrumentos de comunicação entre governo e sociedade. Expressões como Democracia Digital, E-participação, E-democracia, Governança Eletrônica, Ciberdemocracia, entre outras, têm se somado e dialogado com as perspectivas participativas e deliberativas da teoria democrática ao analisarem os potenciais de incremento da participação política proporcionado pela infra-estrutura tecnológica das redes digitais (Gomes, 2005; Dahlberg, 2011). Nesse campo, a ideia de Governo Aberto, embora incorpore e reconheça a importância da dimensão tecnológica da participação, busca superar os limites e desafios organizacionais, tecnológicos e políticos dos governos tendo em vista a criação de um modelo de interação sociopolítica pautado nos princípios da transparência, participação e colaboração nos processos de implementação, controle e avaliação de políticas públicas (Lee \& Kwak, 2011; Cruz-Rubio, 2015). Assim, a expressão de demandas presenciais e digitais implicaria em algum grau de coordenação, diálogo e interlocução na formação de redes colaborativas e comunicativas entre Estado e sociedade.

Convém destacar que, no Brasil, boa parte das interfaces criadas foi se estruturando como modelos participativos que foram replicados, embora as especificidades regionais e locais, em todo o território nacional. Os anos de 1990 foram marcados por um processo de reforma do Estado que, fortalecido pela agenda internacional ligada ao New Public Management (Nova Gestão Pública/NGP), com forte estímulo de agências internacionais, como o Banco Mundial, desempenhou um papel central na transferência da noção de governança como um instrumento para promover reforma econômica de corte neoliberal (Zurbriggen, 2014; Oliveira, Lotta \& Cavalcante, 2016). “A ideia central era a necessidade de ampliação da transparência e responsabilização dos agentes estatais, elemento imprescindível para que o Estado atuasse de maneira mais condizente com um contexto democrático" (Oliveira, Lotta \& Cavalcante, 2016, p.16). Como resultante, testemunhamos a ampliação dos espaços de troca de fluxos de informação entre agências estatais e setores sociais com diferentes propósitos, interesses e estratégias políticas, e em diferentes contextos e dinâmicas sociopolíticas, conformando um quadro de fragmentação, dispersão e de superposição institucional. Como analisado por Pó e Abrucio (2006), a replicação das interfaces em diferentes setores e agências estatais no Brasil, geralmente ocorre por meio de uma espécie de mimetismo, caracterizado pela reprodução de modelos em contextos diferentes, e sem avaliar as suas sobreposições.

O reconhecimento da necessidade de uma maior integração mobilizou, a partir de iniciativas do governo federal de Dilma Rousseff, um processo de discussão para a construção de um sistema de participação que culminou no Decreto n. 8.243/2014 visando instituir uma Política e um Sistema Nacional de Participação Social (PNPS) incorporando, além dos conselhos e conferências, outros instrumentos de participação, como os fóruns, audiências públicas e ambientes virtuais. Os avanços daquela proposta de construção de um sistema participativo, em que pesem alguns de seus limites ${ }^{3}$, e de sua esmagadora derrota política consagrada pela emissão, no atual governo conservador de Jair Bolsonaro, de um decreto substitutivo que promove a extinção de várias instâncias participativas, demonstrava uma forte sensibilidade à necessidade de maior articulação e coordenação entre as diferentes interfaces socioestatais.

Em que pese os atuais retrocessos no campo da participação institucional, o fato é que convivemos com um rico, porém desconexo legado de interfaces 
coletivizados - de participação e consulta, e "que poderiam contribuir para a oxigenação dos demais processos de representação coletiva" (Almeida, 2017, p.663). socioestatais construídas nessas últimas décadas no país: conselhos, conferências, OPs, ouvidorias, consultas públicas, audiências públicas e dispositivos digitais têm materializado diferentes encontros entre setores sociais e governamentais, com origens, atribuições e formatos muito diversos. Além desses formatos mais institucionalizados, os estudos também vêm analisando as modalidades de interface de caráter mais informal, a exemplo das relações - colaborativas e/ou conflitivas - entre movimentos sociais e agências governamentais (Abers, Serafim \& Tatagiba, 2014; Carlos, Dowbor \& Albuquerque, 2017).

Voltado exclusivamente para as interfaces criadas no interior dos aparatos governamentais, e instigado pela identificação da ocorrência de diálogo entre essas interfaces, o presente trabalho apresenta, como resultado de pesquisa sobre as "interfaces das interfaces socioestatais" (CNPq), alguns dados que apontam para diferenças importantes entre as interfaces na sua capacidadede de promover maior articulação, e que são decorrentes de alguns fatores, quais sejam: as diferentes competências e atribuições, as trajetórias e características das áreas de políticas públicas, os desenhos institucionais, e o papel dos atores políticos, burocráticos e sociais.

Visando capturar elementos empíricos suscitados por essa preocupação, a pesquisa recortou, a partir de um mapeamento geral dos diferentes programas e dispositivos de interfaces socioestatais no âmbito do governo do Estado de Santa Catarina e da Prefeitura Municipal de Florianópolis, três modalidades de interfaces, quais sejam, as ouvidorias, os conselhos gestores e os Facebooks governamentais. $\mathrm{O}$ estudo privilegiou o mapeamento das interfaces socioestatais em dois níveis de governo (municipal e estadual), investigando essas três modalidades em diferentes áreas de políticas públicas, quais sejam, saúde, assistência social e meio ambiente. Como sugerido no estudo de Pires e Vaz (2014), há diferenças no padrão de interfaces de acordo com a área da política pública, em especial entre as áreas voltadas para a Proteção e Promoção Social (saúde, assistência social e educação) e as áreas de Desenvolvimento Econômico e Infraestrutura. Além de contarem com interfaces mais coletivas e deliberativas, áreas como as de saúde e assistência social registram uma trajetória de participação em conselhos mais universalizada, estruturada e sistêmica. Destaque para a importância da indução federal (Gurza, Lavalle \& Barone, 2015) e para o papel desempenhado pelas respectivas comunidades de política (Côrtes, 2015; 2017).

Inspirada pelas dimensões analíticas anteriormente apresentadas, a pesquisa se alicerçou nas seguintes perguntas: qual é o sentido e o papel dessas diferentes interfaces no interior de um conjunto mais amplo de mecanismos e instituições participativas? Em que medida essas interfaces dialogam entre si, garantindo algum nível de retroalimentação, ou são criadas de forma isolada e fracionada, obedecendo a distintas lógicas e interesses político-governamentais? Quais sãos os fatores que operam na maior ou menor conexão entre elas?

A pesquisa contou com duas fases de levantamento de dados e informações. A primeira fase buscou realizar um mapeamento geral das interfaces a partir de pesquisa na internet, nas respectivas páginas das Secretarias de Governo nas áreas da saúde, assistência social e meio ambiente, nas esferas estadual e municipal. A análise de documentos permitiu identificar características do desenho institucional e as competências e atribuições das interfaces investigadas. $\mathrm{Na}$ segunda fase, e tendo em vista identificar conexões entre as três modalidades de interfaces socioestatais, foram realizadas, além de conversas e encontros mais informais, 15 entrevistas com os diferentes operadores das interfaces (ouvidores, secretários de conselhos e operadores de Facebook), visando levantar informações sobre objetivos, funcionamento e relações com outras interfaces socioestatais. No caso dos conselhos gestores, a pesquisa também contou com o 
${ }^{4}$ Um maior detalhamento sobre as diferenças entre as expressões interfaces socioestatais e instituições participativas encontra-se em Luchmann, 2020. mapeamento dos registros, nas Atas das reuniões (referentes aos anos de 2017 e 2018), de menções a outras interfaces, quais sejam: conselhos, conferências, consultas públicas, audiências públicas, planos diretores, Câmara de Vereadores, Assembleia Legislativa, ouvidorias, fóruns da sociedade civil, Facebooks, blogs e outros dispositivos online. Essa lista de interfaces também foi utilizada para o mapeamento dos registros de interfaces junto aos Facebooks governamentais. No caso da esfera estadual, foram mapeados os Facebooks das secretarias estaduais da saúde, assistência social e do Instituto de Meio Ambiente, setor responsável pela política de meio ambiente no âmbito estadual (de janeiro de 2018 a abril de 2019). Para o caso de Florianópolis, pesquisamos as postagens do Facebook da Prefeitura Municipal, (PMF) no mesmo período, uma vez que as secretarias das três áreas, no âmbito da PMF, não contarem com páginas próprias no Facebook.

Tendo em vista apresentar os resultados da pesquisa, o trabalho está dividido em três partes. A primeira parte apresenta o conceito de interfaces socioestatais $^{4}$ em diálogo com elementos do campo da teoria democrática e das políticas públicas que dão alicerce às categorias analíticas que julgamos oportunas, mediante os achados empíricos, para a análise sobre as interfaces das interfaces socioestatais. A segunda parte está reservada para a apresentação dos resultados da pesquisa junto às três modalidades de interfaces, seguida, na terceira e última parte, da apresentação de um quadro geral que sistematiza os principais achados do estudo, destacando as principais diferenças encontradas.

\section{Interfaces socioestatais, teoria democrática, governança e políticas públicas}

${ }^{5}$ Essas diferenças não significam, necessariamente, que algumas interfaces sejam a priori mais importantes do que outras. Como exemplificado por Gurza Lavalle e Isunza Vera (2010), os sistemas de queixas podem ser "extremamente útiles no solo para la correción de istorciones administrativas, sino también para la racionalización del poder" (p.34).
Como vimos, são múltiplas as modalidades de participação, incluindo as Instituições Participativas (IP) ${ }^{5}$, a exemplo dos conselhos gestores, orçamentos participativos e as conferências de políticas públicas. O conceito de interfaces socioestatais registra um panorama mais amplo de interações entre Estado e sociedade, incluindo mecanismos e dispositivos individuais, digitais e informais.

Baseados nos trabalhos de Long (1999) e Roberts (2001), Isunza Vera e Hevia (2006) definem o conceito de interface como:

\footnotetext{
"Un espacio de intercambio y conflicto en el que ciertos actores se interrelacionan no casual sino intencionalmente. Un tipo especial de interfaz es el espacio donde actores societales y estatales se encuentran (por lo tanto, las definimos como interfaces socioestatales). Estas interfaces socioestatales están determinadas estructuralmente tanto por la política pública como por los proyectos sociopolíticos de los actores (estatales y societales) concernidos" (Isunza Vera \& Hevia, 2006, p.61).
}

Vemos, nesta definição, três dimensões da ideia de interfaces socioestatais, quais sejam, serem espaços de encontros e/ou comunicação entre atores sociais e governamentais; cujas trocas e intercâmbios não estão isentas de conflitos; e, estarem vinculadas aos diferentes aparatos governamentais, sofrendo, portanto, influências de acordo com a política pública e os interesses e projetos dos diferentes atores - políticos e sociais - envolvidos. Os autores apresentam uma classificação das interfaces que captura uma ampla variedade de modalidades, sejam interfaces de base mais informativa ou política, o que inclui exemplos como as ouvidorias, os sítios na internet, as consultas públicas, as Instituições Participativas (IPs), as plataformas digitais, entre várias outras, materializando diferentes relações entre Estado e sociedade em um cenário com múltiplos pontos de acesso, e preenchido por diferentes formatos e atribuições. Diante desse cenário, encontramos diversas possibilidades de classificação das interfaces, seja pela função e grau de empoderamento (consultivas, deliberativas ou executivas); de formalidade/institucionalização (mais ou menos amparadas por 
${ }^{6}$ De acordo com os autores, as inovações democráticas multicanais são aquelas instituições que projetam diferentes espaços e formatos voltados a diferentes segmentos da população tendo em vista alcançar, ou incluir, setores mais amplos, permitindo a diversificação e a acomodação de demandas e interesses de diferentes tipos de pessoas na sociedade. atos normativos e legislação específica); pelo tipo de inclusão de atores sociais (se indivíduos e/ou grupos); e pelo grau de regularidade (se permanentes ou episódicas) (Pires \& Vaz, 2014; Gurza Lavalle \& Isunza Vera, 2010).

Diante desse quadro, podemos dizer que, e seguindo a reflexão de Hevia e Isunza Vera (2010), se há um déficit de participação, este déficit não parece estar na oferta de espaços e mecanismos participativos, mas sim na forma como eles são utilizados. No campo de estudos sobre teoria democrática e participação, encontramos vários limites e problemas neste sentido, como manipulação política, invisibilidade, desigualdades cognitivas e socioeconômicas, falta de comprometimento político (Fung, 2015; Smith, 2019), além da fragmentação e superposição de funções.

Além de avaliações internas, vários estudos vêm apontando para a necessidade de se olhar para as dinâmicas participativas de uma forma mais abrangente, seja no sentido de analisar os múltiplos canais de engajamento no interior de determinadas inovações democráticas, como são os casos de orçamentos participativos e das assembleias de cidadãos que utilizam diferentes ferramentas participativas (Spada \& Allegretti, 2017) ${ }^{6}$; seja no sentido de analisar as interfaces socioestatais inseridas nas diferentes estruturas de poder político (Almeida \& Tatagiba, 2012; Gurza Lavalle, Houtzager \& Castello, 2006), ou ainda no intuito de situar a sua inserção em um sistema deliberativo (Faria, Silva \& Lins, 2012), ou em uma “arquitetura da participação" (Isunza Vera \& Gurza Lavalle, 2012; Teixeira, Souza \& Lima, 2012).

Avaliando os tipos de interface socioestatal na esfera federal, Pires e Vaz (2014, p.87) apontam para a pertinência da ideia de ecologia, e que "remete à percepção de um sistema complexo, composto por partes/unidades diferenciáveis (tipos) que tendem a desempenhar funções específicas (papéis) e naturalmente se associar às estruturas e ambientes (áreas temáticas) nas quais sua contribuição faça sentido e seja necessária". Encontramos essa ideia de ecologia em debates mais recentes da teoria democrática, como são os estudos sobre os sistemas deliberativos (Dryzek, 2010; Warren, 2012; Hendriks, 2006), ressaltando a necessidade de se reconhecer: a) outros espaços, atores e lógicas de atuação política e seus impactos e relações com procedimentos deliberativos mais específicos; b) as configurações das estruturas de poder político governamental que acomodam e dão ancoragem às instituições e práticas deliberativas; e c) as conexões entre as diferentes esferas discursivas, consideradas condição sine qua non para a existência democrática. Afinal, como ressaltado por Mendonça (2016, p.8), a ideia de sistema implica em que "uma parte deve afetar a outra (s)", o que requer a identificação de indutores de conexão, a exemplo da atuação da burocracia, das comunidades e coalisões políticas, da mídia, além dos desenhos e regras institucionais (Mendonça, 2016; Faria, 2017).

No âmbito dos estudos sobre governança, modelos como os de Governo Aberto e Redes de Governança (Lee \& Kwak, 2011; Cruz-Rubio, 2015; Cavalcante \& Camões, 2015; Sorensen \& Torfing, 2007) se aproximam de perspectivas mais integradoras e coordenadas de processos deliberativos. Em que pesem as diferentes denominações, o enfoque mais geral está voltado para o incremento de processos de controle social e de accountability nos quais "o cidadão passa a desempenhar um papel de mais destaque se comparado à visão de 'cliente', inicialmente propagada pelo NGP" (Cavalcante \& Camões, 2015, p.10), o que demandaria a criação de espaços de participação que promovam a colaboração e a interação entre governo e sociedade nos processos de implementação, controle e avaliação de políticas públicas, consolidando governos relacionais a partir de redes colaborativas como formas predominantes de conduta sociopolítica dos assuntos públicos (Cruz-Rubio, 2015). 
7 Dentre os atores conectores, o estudo de Silva e Ribeiro (2016), focado em 22 conselhos de políticas públicas da cidade de Belo Horizonte (MG), encontrou o predomínio dos conselheiros representantes governamentais.
Nesse debate voltado para a ideia de um sistema interconectado e integrado, Sorensen e Torfing (2007) apontam para uma característica importante, qual seja, a de que as redes de governança se constituem como processos complexos e dinâmicos cujas forças, em muitos casos, se minam mutuamente, confirmando o reconhecimento de que a tomada de decisão política não se limita às estruturas formais do governo, e de que as políticas públicas são formuladas e implementadas por meio de um conjunto diferenciado de instituições, mecanismos e processos, sejam formais e informais; permanentes e episódicos. Assim, distintos de padrões centralizados e hierárquicos de governo, esses processos são multidimensionais, conformando multi-camadas que contam com múltiplos atores e pontos de acesso junto aos diferentes setores de políticas públicas (Sorensen \& Torfing, 2007). No campo das políticas públicas, noções com as de redes e/ou comunidades de políticas procuram espelhar essa complexidade, reconhecendo que os processos decisórios ocorrem de forma segmentada e com a participação de diferentes setores sociais, além dos agentes governamentais (Cortes, 2015). Mesmo no âmbito de cada modalidade de interface, e que conta com um grau razoável de uniformização, a exemplo dos conselhos, não encontramos maior capacidade de articulação. Pesquisa de Corrêa (2012), por exemplo, voltada para a análise das interfaces entre as áreas da educação, assistência social e criança e adolescente conclui que "os Conselhos fatiam, seguindo a lógica de suas respectivas áreas, a dimensão complexa e relacional do social. Assim, não integram suas ações, não se comunicam e não se articulam" (Corrêa, 2012, p.115). Em boa medida, as conexões, quando ocorrem, são derivadas da atuação múltipla dos atores (conselheiros) que assumem cadeiras nesses espa$\operatorname{ços}^{7}$.

Convém ainda assinalar para os diferentes momentos, objetivos, sentidos e funções de criação das interfaces em relação ao ciclo de políticas públicas. De acordo com Comparato (2016), mesmo que de forma limitada, boa parte das interfaces, a exemplo dos conselhos, audiências públicas e leis de iniciativa popular, atuam nos estágios iniciais do ciclo das políticas públicas, contribuindo para a formação da agenda. Já outras modalidades, como os plebiscitos, referendos e instâncias do orçamento participativo podem contribuir para a tomada de decisão. Distintas desses mecanismos, as ouvidorias, por exemplo, atuam no momento da implementação das políticas, constituindo-se como "um instrumento valioso para os gestores públicos, que têm à disposição uma ferramenta muito útil para saber de que maneira os programas governamentais chegam ao cidadão e como este enxerga as mais variadas prestações de serviços públicos" (Comparato, 2016, p.49).

Destaque para o crescimento das ferramentas digitais nesse campo, o que vem estimulando o desenvolvimento de estudos sobre democracia digital e o funcionamento das diferentes modalidades de e-participação como novas oportunidades de consulta e diálogo entre governos e cidadãos (Medaglia, 2012). Nesse campo de debate encontramos, para além de diferentes concepções (Dahlberg, 2011) e graus (Gomes, 2005) de democracia digital, vários limites no uso dessas ferramentas, como as desigualdades de acesso e de controle, a manipulação e a fragmentação da informação (Papacharissi, 2002). Novos termos, como o de polity simulation (simulação de política) vêm sendo criados para identificar a sofisticação na manipulação de informações (áudios, textos e imagens) na internet, gerando riscos à própria democracia, em especial em sociedades com baixo nível de escolarização (Deep Fakes são ameaça no horizonte, 2018).

No caso dos sites governamentais, seu uso tem servido mais como "dispositivos de informação" (Meneses \& Cardoso, 2018) voltados ao marketing político, ou ainda mais como "meios de delivery dos serviços públicos do que formas de acolhimento da opinião do público com efeito sobre os produtores de 
decisão política" (Gomes, 2005, p.221). Além disso, na medida em que esses meios digitais são acrescentados em meio a vários outros dispositivos, há que se analisar as tensões entre eles. De toda forma, "por mais que a internet ofereça inéditas oportunidades de participação na esfera política, tais oportunidades serão aproveitadas apenas se houver uma cultura e um sistema políticos dispostos (ou forçados) a acolhê-los" (Gomes 2005, p.221).

Um elemento comum a essas diferentes modalidades de interfaces socioestatais é o seu vínculo com o aparelho estatal, uma vez que estamos tratando de mecanismos ou instituições que operam no interior do aparato governamental. Essa inserção governamental tem implicações centrais na análise acerca da maior ou menor capacidade articulatória desse campo, em especial, a partir do reconhecimento de que: a) o Estado caracteriza-se por múltiplos e diferentes níveis de organização, e que operam em meios estruturais que sofrem diferentes tipos de influência e de pressão social (Evans, Rueschmeyer \& Skocpol, 1985; Migdal, 1994); b) a volatilidade política resultante do processo eleitoral, o que amplifica dinâmicas erráticas na criação, manutenção e evolução institucional, com impactos importantes no campo das interfaces socioestatais (Frey 2000; Levitsky \& Murillo, 2013); c) além dos atores políticos, há também que se considerar o papel das/os burocratas estatais nos processos de formulação, implementação e avaliação das políticas, na medida em que os estudos apontam a discricionaridade dos burocratas, sejam os de nível de rua (street level bureaucrats, Lipsky, 1980), sejam os de médio escalão, mostrando como esses atores tanto podem promover inovações e soluções de problemas emergentes, como podem também reproduzir situações de desigualdade e de subordinação à posições sociais estruturais (Pires, 2019); d) além dos diferentes níveis de governo - municipal, estadual e federal -, o Estado operacionaliza as suas atividades por meio da setorialização das diferentes áreas de políticas públicas, e que apresentam diferenças em termos de trajetória, recursos e poder. Como apontado anteriormente, essas diferenças trazem rebatimentos importantes no campo da participação. Voltado para o nível federal, o estudo de Pires e Vaz (2014) registrou a ocorrência de um certo padrão entre tipos de interfaces e áreas de políticas públicas: "enquanto interfaces como conselhos e conferências apresentaram maior vínculo relativo aos programas da área de Proteção e Promoção Social, audiências e consultas públicas e reuniões com grupos de interesse se apresentaram mais associadas às temáticas de Infraestrutura e Desenvolvimento Econômico, respectivamente" (Pires \& Vaz, 2014, p.86). Essas diferenças também foram encontradas no estudo sobre a realidade mexicana, identificando uma maior diversidade de interfaces socioestatais no campo das políticas sociais, ao contrário dos campos da seguridade pública e da política fiscal e financeira (Hevia \& Isunza Vera, 2010); e) a dimensão do desenho institucional, ou das regras, critérios e normas de operacionalização da participação, e que envolvem as formas como incorporam os cidadãos e/ou as associações e a articulação com outras interfaces socioestatais (Lüchmann, 2014; 2020; Smith, 2019; Mendonça, 2016; Faria 2017); e f) o papel desempenhado por redes de comunidades de políticas e por atores sociais (Cortes, 2015; Faria, 2017). De forma mais ou menos combinada, essas dimensões são consideradas elementos importantes para a compreensão da ocorrência de maior ou menor conexão entre as diferentes interfaces socioestatais.

\section{Interfaces Socioestatais: ouvidorias, conselhos gestores e Facebooks governamentais}

Tendo em vista identificar os diferentes programas e dispositivos de interfaces socioestatais no âmbito das Secretarias de Saúde, Assistência Social e Meio Ambiente do governo do Estado de Santa Catarina e da Prefeitura Municipal de Florianópolis, apresentamos nos Quadros 1 e 2, além das informações referentes a essas áreas de políticas públicas, informações sobre a ocorrência de 
Quadro 1 - Interfaces identificadas nas Secretarias Estaduais do Governo de Santa Catarina

\begin{tabular}{|c|c|c|c|c|}
\hline $\begin{array}{l}\text { Secretaria da } \\
\text { Segurança } \\
\text { Pública } \\
\end{array}$ & $\begin{array}{c}\text { Secretaria da } \\
\text { Administração }\end{array}$ & Secretaria da Saúde & $\begin{array}{c}\text { Secretaria do Desenvol- } \\
\text { vimento Econômico } \\
\text { Sustentável }\end{array}$ & $\begin{array}{c}\text { Secretaria da Assistência } \\
\text { Social, Trabalho e } \\
\text { Habitação }\end{array}$ \\
\hline \multirow[t]{16}{*}{ Ouvidoria } & Ouvidoria & Ouvidoria & Ouvidoria & Ouvidoria \\
\hline & Fale Conosco & Twitter & Twitter & Twitter \\
\hline & $\begin{array}{l}\text { Telefones e } \\
\text { Webmail }\end{array}$ & Facebook & $\begin{array}{l}\text { Conselho Estadual do Meio } \\
\text { Ambiente de Santa Catarina } \\
\text { (CONSEMA/SC) }\end{array}$ & Facebook \\
\hline & & Consulta Pública & $\begin{array}{c}\text { Fórum Catarinense de } \\
\text { Mudanças Climáticas } \\
\text { Globais (FCMCG) }\end{array}$ & Youtube \\
\hline & & $\begin{array}{l}\text { Conselho Estadual de } \\
\text { Saúde (1990) }\end{array}$ & $\begin{array}{l}\text { Conselho Estadual de } \\
\text { Combate à Pirataria de Santa } \\
\text { Catarina (CECOP/SC) }\end{array}$ & $\begin{array}{l}\text { Conselho Estadual do Idoso } \\
\text { - CEI/SC (1990) }\end{array}$ \\
\hline & & Conferências de Saúde & $\begin{array}{c}\text { Comissão Interinstitucional } \\
\text { de Educação Ambiental do } \\
\text { Estado de Santa Catarina } \\
\text { (CIEA/SC) }\end{array}$ & $\begin{array}{l}\text { Conselho Estadual de Assis- } \\
\text { tência Social- CEAS (1995) }\end{array}$ \\
\hline & & $\begin{array}{l}\text { Comitê de Monitoramento } \\
\text { e Resolução das Deman- } \\
\text { das de Assistência da } \\
\text { Saúde de Santa Catarina }\end{array}$ & $\begin{array}{c}\text { Conselho Estadual de } \\
\text { Recursos Hídricos (CERH) }\end{array}$ & $\begin{array}{c}\text { Conselho Estadual de Tra- } \\
\text { balho e Emprego CETE/SC } \\
\text { (1995) }\end{array}$ \\
\hline & & & $\begin{array}{l}\text { Fórum Estadual Permanente } \\
\text { das Microempresas, e Em- } \\
\text { presas de Pequeno Porte e } \\
\text { dos Empreendedores Indivi- } \\
\text { duais do Estado de Santa } \\
\text { Catarina }\end{array}$ & $\begin{array}{l}\text { Conselho Estadual dos } \\
\text { Direitos da Mulher - } \\
\text { CEDIM/SC (1999) }\end{array}$ \\
\hline & & & & $\begin{array}{l}\text { Conselho Estadual das } \\
\text { Populações Afro descen- } \\
\text { dentes de Santa Catarina } \\
\text { CEPA/SC (2001) }\end{array}$ \\
\hline & & & & $\begin{array}{l}\text { Conselho Estadual dos Di- } \\
\text { reitos da Criança e do Ado- } \\
\text { lescente CEDCA/SC (2002) }\end{array}$ \\
\hline & & & & $\begin{array}{c}\text { Conselho Estadual de Segu- } \\
\text { rança Alimentar e } \\
\text { Nutricional de Santa } \\
\text { Catarina CONSEA/SC } \\
\text { (2004) }\end{array}$ \\
\hline & & & & $\begin{array}{l}\text { Conselho Estadual do Arte- } \\
\text { sanato e Economia Solidária } \\
\text { - CEAES/SC (2009) }\end{array}$ \\
\hline & & & & $\begin{array}{l}\text { Conselho Estadual de } \\
\text { Direitos Humanos } \\
\text { CEDH/SC (2014) }\end{array}$ \\
\hline & & & & $\begin{array}{c}\text { Conselho Estadual dos } \\
\text { Povos Indígenas CEPIN/SC } \\
\text { (2014) }\end{array}$ \\
\hline & & & & $\begin{array}{l}\text { Conselho Estadual da } \\
\text { Juventude CONJUVE/SC }\end{array}$ \\
\hline & & & & $\begin{array}{l}\text { Conselho Estadual dos } \\
\text { Direitos da Pessoa com } \\
\text { Deficiência - CONEDE }\end{array}$ \\
\hline
\end{tabular}


Quadro 2 - Interfaces identificadas nas Secretarias Municipais da Prefeitura de Florianópolis

\begin{tabular}{|c|c|c|c|c|}
\hline $\begin{array}{l}\text { Secretaria de } \\
\text { Segurança } \\
\text { Pública }\end{array}$ & $\begin{array}{c}\text { Secretaria da } \\
\text { Administração }\end{array}$ & Secretaria da Saúde & $\begin{array}{l}\text { Secretaria de Meio Ambien- } \\
\text { te, Planejamento e Desenvol- } \\
\text { vimento Urbano }\end{array}$ & $\begin{array}{c}\text { Secretaria de Assistência } \\
\text { Social }\end{array}$ \\
\hline \multirow[t]{11}{*}{ Ouvidoria } & Ouvidoria & Ouvidoria & Ouvidoria & Ouvidoria \\
\hline & & $\begin{array}{l}\text { Conselho Municipal } \\
\text { de Saúde (CMS) }\end{array}$ & $\begin{array}{c}\text { Conselho Municipal de Defesa } \\
\text { do Meio Ambiente } \\
\text { (CONDEMA) }\end{array}$ & $\begin{array}{l}\text { Conselho Municipal de Assis- } \\
\text { tência Social (CMAS) }\end{array}$ \\
\hline & & $\begin{array}{c}\text { Pesquisa de Satisfação } \\
\text { do Usuário }\end{array}$ & Plano Diretor & $\begin{array}{l}\text { Conselho Municipal dos Direi- } \\
\text { tos da Criança e do Adoles- } \\
\text { cente (CMDCA) }\end{array}$ \\
\hline & & $\begin{array}{l}\text { Denúncia Vigilância } \\
\text { Sanitária }\end{array}$ & Serviços On-Line & Conselho Tutelar \\
\hline & & “Tá sabendo? & Disk denúncia & $\begin{array}{l}\text { Conselho Municipal dos Di- } \\
\text { reitos da Mulher (COMDIM) }\end{array}$ \\
\hline & & Serviços On-Line & & $\begin{array}{c}\text { Conselho Municipal de Promo- } \\
\text { ção da Igualdade Racial } \\
\text { (COMPIR) }\end{array}$ \\
\hline & & $\begin{array}{l}\text { Mesa de negociação } \\
\text { permanente do SUS }\end{array}$ & & $\begin{array}{c}\text { Conselho Municipal dos Direi- } \\
\text { tos da Pessoa com Deficiência } \\
\text { (CMDPD) }\end{array}$ \\
\hline & & & & $\begin{array}{l}\text { Conselho Municipal de Segu- } \\
\text { rança Alimentar e Nutricional } \\
\text { Sustentável (CONSEAS) }\end{array}$ \\
\hline & & & & $\begin{array}{c}\text { Conselho Municipal de Direi- } \\
\text { tos LGBT }\end{array}$ \\
\hline & & & & $\begin{array}{l}\text { Conselho Municipal do Idoso } \\
\text { (CMI) }\end{array}$ \\
\hline & & & & Disk denúncia \\
\hline
\end{tabular}

Fonte: Elaborado pela autora.

${ }^{8}$ Mapeamento realizado nos sites dos governos estadual (SC) e municipal (Florianópolis), em 2018.

${ }^{9}$ Embora haja os links de acesso ao Facebook e outros dipositivos online, os mesmos são referentes à Prefeitura Municipal, e não às respectivas Secretarias. interfaces em outras duas áreas - segurança e administração - que apresentam, ao contrário das selecionadas, o menor número de interfaces socioestatais ${ }^{8}$.

Como podemos visualizar, há diferenças significativas entre as diferentes áreas de políticas públicas, tanto em termos numéricos quanto no que diz respeito às modalidades de interfaces socioestatais encontradas. Vemos que as ouvidorias se constituem como a única modalidade que comparece em todas as áreas, nos dois níveis de governo. Podemos perceber também algumas diferenças e similaridades entre a esfera estadual e municipal. No caso das diferenças, encontramos algumas interfaces no âmbito estadual como o Twitter, o Facebook e os fóruns, que não foram identificadas nas páginas das secretarias do governo municipal ${ }^{9}$. No caso das similaridades, encontramos, nas duas esferas de governo, os desníveis entre as áreas, conforme já destacado, em especial na assistência social, em função do registro de diversos conselhos que representam demandas de diferentes setores e segmentos sociais. Destaque também para uma maior variedade de interfaces nas áreas da saúde e de meio ambiente.

A maioria das interfaces mapeadas não apresenta competência decisória, portanto, de poder de tornar as suas proposições em caráter vinculante. Dentre as três modalidades mapeadas, apenas os conselhos gestores cumprem essa função. Esse reconhecimento é importante tendo em vista que não se pode exigir atribuições para além daquelas para as quais foram criadas. Avaliar uma ouvidoria implica em analisar a sua capacidade de ouvir, processar e responder às demandas dos cidadãos, diferente daqueles conselhos gestores que foram 
criados para discutir, formular e aprovar políticas públicas a serem levadas a cabo pelo poder governamental. Diante disso, um olhar relacional pretende analisar em que medida, por exemplo, os espaços de discussão e de formulação de políticas, a exemplo dos conselhos, são alimentados por canais institucionais que recolhem diferentes demandas, denúncias e queixas sociais, a exemplo das ouvidorias e dos Facebooks governamentais.

\section{III.1. As ouvidorias do poder executivo}

${ }^{10}$ Segundo Alves Júnior (2002, p.47) "A rigor, o Ouvidor não tem poderes e sim atribuições, com direitos a elas inerentes, como os de solicitar informações e requisitar documentos dos órgãos envolvidos, fiscalizá-los e assim por diante".
As ouvidorias, e apesar da diversidade de formatos e de modelos (Lyra, 2016), são instâncias de controle e de participação social responsáveis "pelo tratamento das reclamações, solicitações, denúncias, sugestões e elogios relativos às politicas e aos serviços públicos, prestados sob qualquer forma ou regime, com vistas ao aprimoramento da gestão pública" (CGU, 2014). As ouvidorias se caracterizam como um dispositivo participativo de natureza sigilosa e individual, ao contrário de outros espaços participativos que estão assentados em regras de participação pública e coletiva. Além de não contarem com a participação ativa da sociedade civil, não têm poder decisório e deliberativo, sendo que a principal função está relacionada com a correção e/ou aperfeiçoamento das políticas e dos serviços públicos ${ }^{10}$.

Em estudo específico sobre as interfaces das ouvidorias (Lüchmann, Abrao \& Kieling, 2019), ressaltamos algumas características no âmbito do poder estadual (SC) e municipal (PMF), apontando algumas diferenciações legais com relação à esfera nacional. Em nível federal destacamos, entre outras, a atribuição das ouvidorias em "promover articulação, em caráter permanente, com instancias e mecanismos de participação social, em especial, conselhos e comissões de políticas públicas, conferências nacionais, mesas de diálogo, fóruns, audiências, consultas públicas e ambientes virtuais de participação social" (Instrução Normativa da Controladoria-Geral da União (IN-CGU)

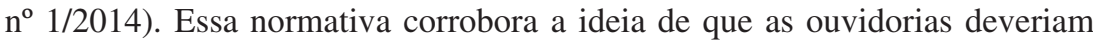
desempenhar papel de destaque no conjunto mais amplo de espaços de participação cidadã na gestão do Estado brasileiro, conforme apontam Menezes e Cardoso (2016), uma vez que "não raras vezes, uma demanda individual aponta para uma expressão ou problema coletivo. Assim, poderá significar uma janela de oportunidade para o desencadeamento de processos que culminem no aperfeiçoamento da administração pública com benefícios para toda a coletividade" (Menezes \& Cardoso, 2016 p.64).

No âmbito do governo do Estado de Santa Catarina foi criado, por meio do Decreto de Lei $\mathrm{n}^{\circ} 1027$ (2008), um sistema administrativo de ouvidorias, centralizando, na Secretaria de Estado da Administração - SEA -, todas as informações e denúncias que são direcionadas aos diferentes setores governamentais. Além do Ouvidor Geral, cargo preenchido por indicação política, a ouvidoria estadual conta com uma estrutura formada por um assistente de ouvidoria, um administrador, dois atendentes terceirizados no atendimento telefônico do 0800 e sete servidores (Michelli, 2016). A centralização das ouvidorias, por meio de uma plataforma digital, gerou, na avaliação do ouvidor geral, uma maior eficácia e controle na gestão dos problemas e demandas sociais. Assim, compondo um sistema de 57 ouvidorias estaduais e 230 seccionais ativas, as diferentes denúncias e/ou manifestações originadas na sociedade são encaminhadas, e cobradas, pelo setor central, aos outros setores da administração estadual.

Não obstante a proposta de sistema proporcionar maior controle e articulação interna entre as ouvidorias dos diferentes setores de políticas, ela avança pouco no sentido de dialogar com outros dispositivos de participação social, o que indica um baixo grau de interface com outras modalidades de participação. 
${ }^{11}$ No que diz respeito à área dos Direitos Humanos, presenciamos um primeiro encontro, por iniciativa do conselho, com a Ouvidoria Geral do Estado tendo em vista não apenas otimizar o fluxo de informações, como tornar mais eficaz o controle social e governamental para a resolutividade dos problemas referentes às violações dos direitos humanos.

${ }^{12}$ De acordo com a "Cartilha Regulamentação e Estrutura Organizacional da Ouvidoria da Secretaria Municipal de Saúde de Florianópolis-SC (2011)", o ouvidor deve apresentar, entre outros, "competência técnica". Dos cinco ouvidores municipais entrevistados para esta pesquisa, dois não possuem a formação adequada sugerida pelo documento.

${ }^{13}$ De acordo com um dos ouvidores entrevistados, em resposta à pergunta sobre quais são as relações [da Ouvidoria] com outros setores/órgãos/interfaces socioestatais, a resposta foi que a ouvidoria "não deve ter relação, ela [a Ouvidoria] deve ser neutra. Se ela se comunicar com conselho vira algo ideológico".
Uma baixa sensibilidade para essa dimensão pode ser encontrada na própria legislação, uma vez que o Decreto do Estado de Santa Catarina está voltado apenas para a promoção de articulação no interior do sistema de ouvidorias. Além disso, como analisado no estudo de Lüchmann, Abrão e Kieling (2019), são raros os momentos de diálogo e de articulação com outras interfaces socioestatais, a exemplo de um movimento de aproximação com os conselhos da área da Assistência Social e de Direitos Humanos ${ }^{11}$ em decorrência da atuação da ouvidora da Secretaria de Assistência Social, com formação em Serviço Social e trajetória de atuação junto ao Conselho Estadual de Assistência Social; seja pela atuação dos representantes - sociais e governamentais - do Conselho Estadual de Direitos Humanos.

Criada em 2007, a Ouvidoria Geral da Prefeitura Municipal de Florianópolis, subordinada à Superintendência de Transparência e Controle, apresenta um quadro bastante limitado em termos de recursos humanos. Além disso, vários ouvidores são servidores públicos que, indicados pelo secretário da pasta, acumulam as duas funções, o que limita o tempo e a dedicação a esta atividade. Nesses casos, também se percebe maior carência de recursos e de infraestrutura para o exercício do cargo. Destaque também para o perfil das/os ouvidores, em alguns casos distante dos requisitos regimentais ${ }^{12}$. Além disso, mudanças administrativas implementadas pelo novo prefeito limitaram garantias deste cargo, a exemplo da dedicação exclusiva, mantida apenas para a Ouvidoria Geral, e promoveram trocas de ouvidores sem formação e acúmulo de conhecimento e experiência no cargo. Como resultado geral, percebemos, a partir de entrevistas com alguns ouvidores, não apenas uma ausência de interlocução com outras interfaces socioestatais, como ao contrário, algumas falas que reforçam a necessidade de isolamento das ouvidorias ${ }^{13}$.

Assim, de maneira geral, podemos dizer que as ouvidorias, tanto no âmbito do governo estadual quanto municipal, têm atuado de forma isolada em relação a outras interfaces socioestatais, em que pese uma ou outra iniciativa no âmbito da ouvidoria estadual. Esse isolamento parece ser decorrente de um conjunto de fatores, quais sejam: a) a trajetória relativamente recente das ouvidorias, o que implica em necessidade de maturação no processo de estruturação; b) as atribuições legais que não comportam, tanto no âmbito estadual como municipal, a promoção de articulação das ouvidorias com outras instâncias e mecanismos de participação social; c) iniciativas da burocracia - não obstante algumas exceções no âmbito estadual, não identificamos interesse, ou iniciativas, por parte de alguns dos operadores das ouvidorias, em promover ações no sentido de oportunizar trocas e diálogos com outras interfaces socioestatais; e d) impactos dos processos e dinâmicas políticas. A troca de ouvidores e as mudanças no desenho institucional acarretadas pela alteração da gestão pública, no caso da Prefeitura Municipal de Florianópolis, têm impedido um acúmulo de conhecimento e experiência, dificultando também o diálogo com outras interfaces socioestatais.

III.2. Interfaces nos conselhos gestores

Os Conselhos Gestores são instituições participativas importantes no cenário das interfaces socioestatais na medida em que, em boa parte dos casos, são amparados por legislação e responsáveis pela discussão e deliberação de políticas públicas em suas respectivas áreas de atuação. A partir da Constituição de 1988, alguns conselhos tornaram-se obrigatórios em áreas de políticas, como saúde, assistência social e criança e adolescente. Desde então, esse modelo participativo veio se expandindo pelo sistema político brasileiro, tornando-se referência para um conjunto mais variado de políticas, mesmo que com especificidades e variações. 
${ }^{14}$ Foram analisadas as atas disponibilizadas pelos conselhos e extraídas as informações referentes à interação com as seguintes categorias: outros conselhos (gestores e/ou de políticas), conferências, consultas públicas, audiências públicas, Câmara de Vereadores (âmbito municipal)/Deputados (estadual), e uso de ferramentas digitais: Twitter, Facebook, Youtube e Blogs. ${ }^{15}$ Informações disponíveis no site oficial do CMS: http://cms.pmf.sc.gov.br/?p=c ms.

\footnotetext{
${ }^{16}$ Informações disponíveis no site oficial do CES-SC: http://www.saude.sc.gov.br/in dex.php/resultado-busca/geral/ 10221-o-conselho-estadual-desaude.
}

Os Conselhos Gestores são, portanto, interfaces socioestatais de caráter público que, ancoradas na participação de setores da sociedade civil organizada, estão voltadas para a discussão, formulação e fiscalização das políticas em suas respectivas áreas de atuação.

No Quadro 3 apresentamos os anos de criação dos Conselhos Gestores nas três áreas, no âmbito do governo estadual de Santa Catarina e do município de Florianópolis.

Como é possível observar, os anos de criação desses conselhos concentram-se no primeiro período de criação dos Conselhos Gestores a partir da Constituição de 1988, entre fins da década de 1980 e fins da década de 1990. Boa parte desses conselhos foi reestruturada no mesmo momento em que novos conselhos surgiam, durante a década de 2000, como os de Direitos da Pessoa com Deficiência, de Promoção da Igualdade Racial e de Direitos das Mulheres.

Antes de apresentarmos o resultado da consulta às Atas de reuniões dos conselhos ${ }^{14}$, selecionamos as informações, nos regulamentos, das competências de cada Conselho no que se refere à ocorrência de interfaces com outros mecanismos participativos.

O Conselho Municipal de Saúde de Florianópolis (CMS) foi criado pela Lei Municipal no 3.291 de 1989, caracterizando-se enquanto um colegiado permanente e deliberativo que propõe, acompanha e fiscaliza as políticas na área da saúde no município ${ }^{15}$. Compete ao Conselho Municipal de Saúde, entre outras atribuições:

I - promover e coordenar em conjunto com a Secretaria Municipal de Saúde, a cada quatro anos, ou em caráter extraordinário, quando necessário, a Conferência Municipal de Saúde, bem como, as demais conferências da área da saúde;

II - promover e coordenar, em conjunto com a Secretaria Municipal de Saúde, anualmente, o Fórum dos Conselhos Locais de Saúde do Município de Florianópolis;

III - apoiar a criação, organização e acompanhamento do funcionamento dos conselhos locais e distritais de saúde, decorrentes do processo de descentralização no âmbito do município de Florianópolis.

O Conselho Estadual de Saúde de Santa Catarina (CES-SC) foi criado em junho de 1993, conforme determinação da Lei nº 9.120 e caracteriza-se enquanto órgão colegiado permanente e deliberativo. Ao conselho competem as funções de fiscalizar e formular estratégias referentes à execução da política estadual de saúde: ${ }^{16}$ De acordo com o Art. $4^{\circ}$, são atribuições do Conselho Estadual de Saúde, entre outras:

Quadro 3 - Ano de criação dos Conselhos Gestores

\begin{tabular}{lcc}
\hline Âmbito & Área do Conselho & Ano de Criação \\
\hline Município de Florianópolis & Saúde & 1989 \\
& Defesa do Meio Ambiente & 1995 \\
& Assistência Social & 1996 \\
Governo do Estado de & Saúde & 1993 \\
Santa Catarina & & 1993 \\
& Defesa do Meio Ambiente & 1995 \\
\hline
\end{tabular}

Fonte: Elaboração a partir dos documentos dos Conselhos. 
VII - articular-se com a secretaria de Estado da Educação, Cultura e Desporto e com o Conselho Estadual de Educação quanto à criação de novos cursos de ensino superior na área da saúde, no que concerne à caracterização das necessidades sociais do Estado;

XIII - Convocar, em caráter extraordinário, a Conferência Estadual de Saúde, nos termos da Lei $\mathrm{n}^{\circ}$ 8.142, de 28 de dezembro de 1990 (SANTA CATARINA, 1993).

O Conselho Municipal de Assistência Social (CMAS) de Florianópolis foi criado em 1996, de caráter obrigatório e de composição paritária entre sociedade civil e Estado. O conselho se configura como órgão colegiado deliberativo e permanente e as suas atribuições são, de acordo com o Art. $4^{\circ}$ da Lei $n^{\circ} 8049$, 19 de novembro de 2009, compete ao conselho:

XI - convocar a conferência municipal de assistência social, conforme as diretrizes estabelecidas pelo Conselho Nacional de Assistência Social (CNAS), bem como aprovar as normas de funcionamento das mesas, constituir a comissão organizadora e o respectivo regimento interno;

XXIII - estabelecer e fortalecer a interlocução com os demais Conselhos das políticas setoriais.

O Conselho Estadual de Assistência Social (CEAS) de Santa Catarina foi criado em 1995 e configura-se enquanto um órgão colegiado permanente e deliberativo, de composição paritária. De acordo com a Lei n 10.037 (26 de dezembro de 1995), alterada pela Lei no $10.793 / 98$ (2014), compete ao CEAS, entre outros:

IX - articular-se com os Conselhos Nacional e Municipais de Assistência Social, bem como com organizações da sociedade civil, instituições nacionais e estrangeiras, por intercâmbio, convênio ou similar, visando a superação de problemas do Estado;

XI - convocar ordinariamente a cada 02 (dois) anos, ou extraordinariamente, por maioria absoluta dos seus membros, a Conferência Estadual de Assistência Social, que terá a atribuição de avaliar a situação da assistência social no Estado e propor diretrizes para o aperfeiçoamento do sistema;

XVII - acompanhar em conjunto com a Secretaria de Estado do Desenvolvimento Social e da Família a implantação dos Conselhos Municipais, assim como a composição e alteração das respectivas diretorias.

O Conselho Municipal de Defesa do Meio Ambiente de Florianópolis (COMDEMA) foi criado em 1995 como órgão colegiado deliberativo vinculado à Secretaria Municipal de Meio Ambiente e Desenvolvimento Urbano. De acordo com a Lei $n^{\circ}$ 8130/ 2010, não encontramos competência articuladora neste conselho. Da mesma forma, o Conselho Estadual de Meio Ambiente de Santa Catarina (CONSEMA-SC) criado em 1993 como órgão colegiado deliberativo e de participação paritária e associado à Secretaria de Estado do Desenvolvimento Econômico Sustentável (SDS), não apresenta atribuições de interface no plano legal.

Diante disso, vejamos o quadro geral de registro de interfaces identificadas nas Atas dos conselhos (Quadros 4 e 5), tanto no âmbito municipal, como estadual:

A partir da exposição acima, e visando a uma avaliação comparativa que leve em conta as diferenças de nível governamental (Estado e Município) e de áreas de políticas públicas, ressaltamos que:

a) Dentre as três áreas analisadas, a área da Saúde se sobressai nas menções a outras interfaces socioestatais, no plano municipal. Além de manter uma importante conexão com a Câmara de Vereadores, os maiores destaques são para as relações com outros conselhos e com 
Quadro 4 - Registro das interfaces identificadas nas atas dos Conselhos Municipais

\begin{tabular}{lccc}
\hline $\begin{array}{l}\text { Modalidade de in- } \\
\text { terface }\end{array}$ & $\begin{array}{c}\text { CMS }^{\text {II }} \text { (total 21 } \\
\text { atas) }\end{array}$ & $\begin{array}{c}\text { CMAS }^{\text {II }} \text { (total 18 } \\
\text { atas) }\end{array}$ & $\begin{array}{c}\text { CONDEMA }^{\text {II }} \text { (total } \\
\text { 20 atas) }\end{array}$ \\
\hline Outros conselhos ${ }^{\mathrm{I}}$ & 12 & 0 & 4 \\
Conferências & 14 & 8 & 4 \\
Consultas públicas & 3 & 0 & 1 \\
Audiências públicas & 9 & 2 & 1 \\
Plano Diretor & 4 & 0 & 2 \\
Câmara de & 16 & 7 & 1 \\
Vereadores & & & \\
Ouvidoria & 3 & 0 & 0 \\
Fóruns & 9 & 12 & 2 \\
Facebook & 0 & 0 & 1 \\
Blog & 0 & 0 & 0 \\
Youtube & 0 & 0 & 0 \\
Twitter & 0 & 0 & 0 \\
\hline
\end{tabular}

Fonte: Elaborado pela autora a partir dos registros de Atas de reuniões dos conselhos. ${ }^{\mathrm{I}} \mathrm{O}$ registro diz respeito a outros conselhos que se constituem como interfaces socioestatais. Assim, não pontuamos a ocorrência de relações com outros tipos de conselhos, como os profissionais e comunitários.

${ }^{\text {II } C o n s e l h o ~ M u n i c i p a l ~ d e ~ S a u ́ d e ~(C M S) ; ~ C o n s e l h o ~ M u n i c i p a l ~ d e ~ A s s i s t e ̂ n c i a ~ S o c i a l ~}$ (CMAS); Conselho Municipal de Defesa do Meio Ambiente (CONDEMA).

conferências, em boa medida em decorrência da própria legislação, que especifica atribuições neste sentido. Destaque também para algumas características do desenho institucional do sistema conselhista nesta área, uma vez que está estruturado, no âmbito municipal, em conselhos locais, ou distritais, existentes nas quatro regiões da cidade (Centro, Continente, Norte e Sul). Por outro lado, ressaltamos também a sua

Quadro 5 - Registro das interfaces identificadas nas atas dos Conselhos Estaduais

\begin{tabular}{lccc}
\hline Modalidade de interface & CES $^{\text {I }}$ (total 13 atas) & CEAS $^{\text {I }}$ (total 18 atas) & CONSEMA $^{\text {I }}$ (total 16 atas) \\
\hline Outros conselhos & 1 & 7 & 4 \\
Conferência & 8 & 7 & 4 \\
Consulta pública & 5 & 1 & 1 \\
Audiência pública & 2 & 3 & 2 \\
Plano Diretor & 0 & 0 & 4 \\
Câmara de Deputados & 0 & 0 & 1 \\
Ouvidoria & 1 & 4 & 0 \\
Fóruns & 3 & 7 & 3 \\
Facebook & 0 & 0 & 1 \\
Blog & 0 & 0 & 0 \\
Youtube & 0 & 0 & 0 \\
Twitter & 0 & 0 & 0 \\
\hline
\end{tabular}

Fonte: Elaborado pela autora a partir dos registros de Atas de reuniões dos conselhos.

${ }^{\mathrm{I}}$ Conselho Estadual de Saúde (CES); Conselho Estadual de Assistência Social (CEAS); Conselho Estadual de Meio Ambiente (CONSEMA). 
${ }^{17}$ Em entrevista realizada com o Secretário Executivo do CMS (2016), constatamos um forte engajamento e compromisso com as ações do conselho.

${ }^{18}$ O Fórum é um espaço de articulação de associações na cidade, criado em meados da década de 2000, e que congrega aproximadamente 40 entidades que se reúnem, mensalmente, para articular, discutir, propor e demandar políticas e ações orientadas para a defesa e a garantia dos direitos de todos os usuários das diversas áreas das políticas sociais.

${ }_{19}$ Entrevista realizada em 3 de julho de 2018.

\footnotetext{
${ }^{20}$ Em conversa com a Secretária Executiva do CMAS (realizada em 25/02/2019), a mesma confirmou essa ausência de articulação com outros conselhos, em especial nas duas últimas gestões. "O alto número de demandas acaba limitando a capacidade de interlocução com outros conselhos, que também têm suas extensas agendas".

${ }^{21}$ De acordo com a Secretária Executiva do Conselho, "dentro da Secretaria da Assistência Social há uma interface grande com os outros conselhos pois há uma diretoria lá dentro responsável pelos outros conselhos, então estão sempre em comunicação".
}

relação com diversos fóruns e organizações sociais, fruto não apenas da trajetória participativa desta área no país, servindo como modelo para outras áreas de políticas, como também da composição (tripartite) do conselho, formado por uma pluralidade de representantes sociais, profissionais, empresariais e governamentais. Não apenas o perfil desses representantes, mas dos funcionários (secretários do conselho) é também um elemento central, conforme pudemos observar para o caso do CMS de Florianópolis. ${ }^{17}$

b) Ainda no âmbito municipal, a área da Assistência Social ocupa o segundo lugar nos registros de menções a outras interfaces socioestatais, com destaque ao seu envolvimento com os fóruns, a exemplo do Fórum de Usuários do Estado de Santa Catarina, o Fórum Municipal dos Trabalhadores do Sistema Único de Assistência Social - SUAS, e em especial o Fórum Municipal Permanente de Políticas Públicas de Florianópolis $^{18}$. Essa relação próxima com os fóruns também comparece no âmbito estadual. De acordo com a secretária executiva do Conselho Estadual de Assistência Social, "a sociedade civil no conselho estadual de assistência se organiza em três segmentos (fóruns): trabalhadores do SUAS, usuários do SUAS e entidades de assistência social, sendo um papel do conselho estimular a criação de fóruns (...) O Fórum Estadual Permanente de Assistência Social (FEPAS) é onde todos se encontram e debatem a pauta do conselho para identificar se podem contribuir com algo"19. Sugerimos que essas relações apresentam características muito próximas das noções de redes e/ou comunidades de política (Cortes, 2015; Capella \& Brasil, 2015), enquanto articulações entre atores sociais, profissionais e governamentais que atuam e compartilham perspectivas comuns acerca da política. Assim, "as redes representam uma abordagem que, de certa forma, rompe com a dicotomia Estado-sociedade, ao entender que atores pertencentes aos quadros governamentais são também atores sociais e mantêm relações constantes com outros atores numa rede de relacionamentos" (Capella \& Brasil, 2015, p.63). Da mesma forma que a área da saúde, encontramos várias menções às conferências, atendendo as atribuiçõos regimentais. Merece destaque, no entanto, a ausência, no âmbito municipal, de menções a outros conselhos gestores, contrariando atribuições especificadas na legislação ${ }^{20}$. Essa realidade não se reproduz no âmbito estadual, uma vez que registramos várias menções aos diferentes conselhos de direitos vinculados à pasta, fruto de investidas gerenciais e organizacionais ${ }^{21}$.

c) Dentre as três áreas, a do Meio Ambiente é a que apresenta menor número de registros de interfaces socioestatais, tanto no plano municipal como estadual. No caso de menções a outros conselhos e a conferências, destacamos que essas não são atribuições de caráter legal e regimental. No entanto, e tendo em vista as peculiaridades da área, seria de se esperar um envolvimento maior com as modalidades de consultas, audiências públicas e Planos Diretores. Também bastante diferente das áreas da saúde e da assistência social, esses conselhos apresentam menor articulação com outras esferas sociais.

d) No que diz respeito às relações com os legislativos (Vereadores e Deputados), ressaltamos duas observações. Por um lado, a atuação importante, no âmbito municipal, da área da Saúde e, em menor medida, da Assistência Social. Por outro lado, a ausência (nas atas), no âmbito dos conselhos estaduais, em especial nas áreas da saúde e do meio ambiente, de menções relativas ao legislativo estadual. No caso da assistência social, de acordo com a secretária do conselho estadual "há uma comissão na Assembleia, dirigida pela deputada Luciane Carmi- 
natti, que trata dos assuntos da política de assistência social na Câmara dos Deputados e que conta com a participação do Conselho Estadual da Assistência Social".

e) Embora em todos os casos pesquisados tenhamos encontrado poucos registros (ou ausentes) para as ouvidorias, ressaltamos o número, mesmo que ainda baixo, encontrado para o caso do Conselho Estadual de Assistência Social. Vale aqui ressaltar a importância dos perfis, tanto de agentes governamentais quanto da representação social nos conselhos.

f) Finalmente, ressaltamos a quase ausência de registros referentes às ferramentas digitais. No entanto, em consulta aos Facebooks governamentais, identificamos algumas diferenças que merecem atenção, com destaque à área da assistência social em âmbito estadual.

\section{III.3. Facebooks como interfaces socioestatais}

22 Conforme citado por Klenk e Prudencio (2016, p.313), "em palestras e entrevistas concedidas para apresentar seus produtos, os social media da Prefeitura de Curitiba indicaram ter optado por uma estética menos governamental e mais adaptada a lógica das redes sociais; mais bem-humorada (...) em dinâmicas que pudessem favorecer o relacionamento e o 'engajamento"”.
${ }^{23}$ Entre elas: o Conselho Estadual das Populações Afro descendentes, Conselho Estadual dos Direitos da Mulher, Conselho Estadual do Idoso, Conselho Estadual dos Direitos da Pessoa com Deficiência, conselhos tutelares, Conselho Estadual de Trabalho e Emprego, Conselho Estadual de Direitos Humanos, e Conselho Estadual da Juventude.

${ }^{24}$ A atual secretária, por exemplo, além de ter sido
Os Facebooks governamentais são, em geral, interfaces de tipo informativo que promovem algum grau de interação, permitindo reações e manifestações sociais. No entanto, diferente dos conselhos e ouvidorias, que apresentam um caráter legal e formal, constituem-se como um canal de base informal. Fazendo uso de uma linguagem e de uma estética ${ }^{22}$ que são características das redes sociais, apresentam uma vocação voltada especialmente para a informação e a propaganda governamental. Como analisado por Klenk e Prudencio (2016, p.325) em referência à página da prefeitura de Curitiba (Prefs), "não é raro, no perfil da Prefs, encontrar postagens que colocam a página como um usuário comum - não institucional - da rede social”.

Tendo em vista identificar postagens referentes a outras interfaces socioestatais, encontramos diferenças significativas, com destaque ao Facebook da Secretaria Estadual de Assistência Social. No Facebook da Secretaria Estadual de Saúde, não identificamos nenhuma menção ao Conselho Estadual de Saúde, ou a outros conselhos, seja de âmbito nacional ou municipal. No que diz respeito a outras interfaces socioestatais, encontramos apenas duas menções à ouvidoria da Secretaria Estadual de Saúde. No caso do Facebook do Instituto do Meio Ambiente, não encontramos nenhuma menção a conselhos ou ouvidorias, e apenas uma referência a $2^{a}$ Conferência sobre Licenciamento Ambiental e Segurança Jurídica.

Já no caso do Facebook da Secretaria de Estado da Assistência Social, Trabalho e Habitação, a consulta identificou um número muito expressivo de menções à atuação dos conselhos vinculados à pasta. No ano de 2018 identificamos 57 menções à atuação dos diferentes conselhos. Este número parece crescer ainda mais em 2019, uma vez que no período de janeiro a meados de abril encontramos o registro de 22 notícias relacionadas aos conselhos, de diferentes temáticas ${ }^{23}$. Em que pese as especificidades desta secretaria, em especial por abrigar 12 conselhos estaduais, um ponto de destaque parece ser, além da atuação de uma comunidade de política envolvendo atores e setores políticos e sociais, o perfil e a valorização desses espaços por parte da secretária da pasta ${ }^{24}$ e a atuação dos operadores do sistema, que mantêm contato com todas as secretarias dos conselhos vinculados ${ }^{25}$. Menções a conferências (igualdade racial e assistência social) também foram identificadas nas postagens.

No caso da esfera municipal, e tendo em vista a ausência de Facebooks das secretarias municipais, procedemos a um mapeamento das postagens do Facebook da Prefeitura de Florianópolis (195.000 curtidas, em abril de 2019), criada em 15 de abril de 2013, ano que coincide com o nascimento da fanpage de Curitiba (Prefs), e que tem servido de modelo para a capital catarinense ${ }^{26}$. De 
Diretora de Direitos Humanos da SST, atuou em diversos conselhos na área social: Conselho Estadual de Assistência Social; Conselho Estadual do Idoso SC (CEI); Conselho Estadual dos Povos Indígenas SC (CEPIN); Conselho Estadual da Igualdade Racial (CEPA) e Conselho Estadual dos Direitos da Pessoa Portadora de Deficiência SC

(CONEDE).

${ }^{25}$ De acordo com contato telefônico realizado com a administradora do facebook, eles mantêm um grupo de WhatsApp que comporta todos os secretários executivos dos 12 diferentes conselhos vinculados à Secretaria de Assistência Social.

${ }^{26}$ De acordo com a Diretoria de Comunicação da PMF que administra a Página da PMF, a mesma é inspirada em outros modelos, com destaque a Prefs, além das Páginas de Salvador, São Paulo e Rio de Janeiro. De acordo com conversa realizada em $25 / 02 / 2019$ acordo com os "termos de uso", a página teria as seguintes finalidades e diretrizes:

\begin{abstract}
“A Fanpage Oficial da Prefeitura Municipal de Florianópolis tem como principal objetivo ser um espaço para o diálogo com a população e informar sobre ações, serviços e eventos relacionados a Prefeitura e ao Município. A página é um canal aberto ao público que possibilita comentários e interação, desde que estes estejam de acordo com a política de uso" (Fanpage Oficial da Prefeitura Municipal de Florianópolis).
\end{abstract}

A partir da coleta do conteúdo divulgado ao longo dos meses de junho, julho, agosto, até o dia 25 de setembro de 2018, identificamos que os temas que mais se destacaram, em número de publicações, foram: Cultura, com 41 entradas (17\%); Paisagem, 28 (12\%); Saúde, 22 (9\%) e Bem-estar animal, 21 (9\%). No que diz respeito ao registro de outras interfaces, das 241 publicações analisadas, apenas oito (8) fazem menção a outros tipos de interfaces socioestatais, sendo que dessas, sete (7) se referem à rede solidária Somar Floripa ${ }^{27}$, e uma à ouvidoria.

Diante do conjunto da dados e informações, é inegável que o Facebook, ou a fanpage inova na comunicação entre governo e população, propiciando a ampliação de canais de divulgação e de contato com as ações da prefeitura. Trata-se de uma interface de tipo informativo que promove interação, permitindo reações e manifestações. No entanto, diferente dos conselhos e ouvidorias, que apresentam um caráter legal e formal, a fanpage constitui-se como um canal de base informal, com um sentido voltado especialmente para a informação e a propaganda governamental. É inegável também, frente a outras interfaces socioestatais, a capacidade de atingir públicos muito mais amplos, embora sem poder de interferir nas políticas e ações governamentais.

Assim, no que diz respeito às interfaces das interfaces socioestatais, identificamos diferenças importantes entre as distintas modalidades, as áreas de políticas públicas, e os níveis de poder governamental, e que são determinadas pelos objetivos, competências, regras de funcionamento e composição e pelos diferentes perfis, seja dos gestores, funcionários, e atores sociais.

\section{Conclusões: sistematização do quadro das interfaces das interfaces socioestatais}

27 De acordo com o seu site, o Somar Floripa é "uma rede solidária da Prefeitura de Florianópolis que conecta os cidadãos às Organizações da Sociedade Civil - OSCs de Florianópolis para realizar trabalhos voluntários de cuidado das pessoas, da comunidade e dos animais". Disponível em: http://somarfloripa.com/quemsomos/ Acesso em: 09 de mai. 2020

${ }^{28}$ Embora haja os links de acesso ao Facebook e outros dipositivos online, os mesmos são referentes à Prefeitura Municipal, e não à respectiva Secretaria.
No mapeamento mais geral das interfaces encontradas nas diferentes Secretarias de Governo Estadual (Santa Catarina) e Municipal (Florianópolis), podemos dizer que as ouvidorias se constituem como a única modalidade que comparece em todas as áreas mapeadas, nos dois níveis de governo. No caso das outras interfaces, vemos algumas diferenças e similaridades entre a esfera estadual e municipal. No âmbito do governo estadual, encontramos algumas interfaces, como o Twitter, o Facebook e os fóruns, que não foram identificadas nas páginas das Secretarias do governo municipal ${ }^{28}$. Vemos, no caso das similaridades, os desníveis entre as áreas, com destaque para a área da Segurança Pública, a menor em ocorrência de interfaces socioestatais em comparação com a área da Assistência Social. Para esta área, destaque para o registro dos Conselhos de diversos setores e/ou minorias sociais. Destaque também para uma maior pluralidade de interfaces nas áreas da Saúde e de Meio Ambiente.

A partir dos nossos dados, procedemos a uma sistematização das características mais gerais dessas três modalidades, conforme o Quadro 6.

Diante deste quadro, podemos dizer que:

i. As Ouvidorias ocupam um lugar importante nos processos de execução das políticas públicas. Sua principal função é a de ouvir, processar e responder às demandas dos cidadãos com relação ao desempenho da 
Quadro 6 - Características e interfaces das interfaces socioestatais

\begin{tabular}{lccc}
\hline & Ouvidorias & Conselhos gestores & Facebooks \\
\hline Propósitos/competências & $\begin{array}{c}\text { Escuta social, provimento de } \\
\text { informação à população e } \\
\text { fiscalização da gestão }\end{array}$ & $\begin{array}{c}\text { Fiscalização, controle e } \\
\text { deliberação de políticas } \\
\text { públicas }\end{array}$ & $\begin{array}{c}\text { Propaganda governamen- } \\
\text { tal, informação de ações e } \\
\text { interação com a população }\end{array}$ \\
$\begin{array}{l}\text { Lugar no desenvolvimento } \\
\text { das políticas públicas }\end{array}$ & Execução & Formulação, acompanhamento \\
e avaliação & Indefinido \\
$\begin{array}{l}\text { Grau de formalidade } \\
\begin{array}{l}\text { Alcance da participação da } \\
\text { população }\end{array}\end{array}$ & Alto - base legal \\
$\begin{array}{l}\text { Tipo de interação } \\
\text { Tipo de participação } \\
\text { preponderante } \\
\begin{array}{l}\text { Relação Estado-sociedade } \\
\text { Relação com outras inter- } \\
\text { faces socioestatais }\end{array}\end{array}$ & Da sociedade para o Estado & Baixo & Baixo - informal \\
\hline
\end{tabular}

Fonte: elaborado pela autora.

administração pública. Trata-se de uma interface socioestatal com forte grau de responsividade, garantida por lei. A participação é de âmbito privado (sigiloso), e apresenta, crescentemente, certa capacidade de alcance social. No que diz respeito às suas relações com outros mecanismos participativos, ou interfaces socioestatais, encontramos importante grau de "insulamento institucional".

ii. Os Conselhos Gestores ocupam um lugar de destaque nos processos de formulação, deliberação e fiscalização das políticas públicas. Sua principal atribuição é a de promover debates públicos sobre as políticas, fiscalizando a sua execução pela administração governamental. Em que pese o baixo grau de alcance da participação, se comparados aos Facebooks, são os espaços que apresentam maior capacidade de promoção de interfaces com outras instâncias participativas, com destaque para as áreas da Saúde e da Assistência Social.

iii. O Facebook ocupa um lugar periférico na definição e implementação das políticas públicas. Sua principal função é a de interagir, entreter e divulgar notícias, campanhas e determinadas ações governamentais, servindo como importante veículo de propaganda governamental. Trata-se de uma interface socioestatal de base informal, com alta capacidade de alcance social. No que diz respeito às suas relações com outros mecanismos participativos, encontramos diferenças importantes, com destaque positivo para a área (no âmbito estadual) da assistência social.

Além das diferenças entre as três modalidades, encontramos também diferenças, na mesma modalidade, entre as áreas de políticas públicas e os níveis governamentais, e que estão alicerçadas nas trajetórias, competências, recursos, perfis e graus de articulação de atores, e desenhos institucionais. Como vimos, as (extensas) atribuições regimentais dos conselhos de Saúde e Assistência Social incluem, diferente das ouvidorias, dos conselhos de Meio Ambiente e dos Facebooks, atribuições no sentido de atuar e se relacionar junto a outros conselhos, fóruns e conferências. Destaque também para as características do desenho institucional, como a ocorrência de outros espaços participativos (Conselhos Locais de Saúde), as regras de composição, o grau de formalidade e os formatos de interação social. Ressalta-se também a importância do perfil 
político dos governos e, em especial, dos dirigentes e dos agentes (burocracia) que administram as interfaces socioestatais. E ainda, a trajetória histórica de participação e envolvimento social que caracteriza as diferentes áreas de políticas públicas.

Embora os limites do escopo deste estudo, em especial mediante a complexidade dada pela variedade de programas e dispositivos participativos no âmbito das agências e estruturas governamentais e pelas especificidades locais e regionais, o mesmo reforça a importância de se ampliar, de forma relacional, o entendimento desse fenômeno, uma vez que, se é certo que cada uma das modalidades tenha origem, trajetória e características próprias, o fato de serem espaços que, de forma diferenciada, recolhem queixas, opiniões e demandas da população, instiga a se pensar nas possibilidades e limites de promoção de maior diálogo e coordenação, como sugerido por correntes da teoria democrática e da governança.

Lígia Helena Hahn Lüchmann (ligia@cfh.ufsc.br) é Doutora em Ciências Sociais pela Universidade Estadual de Campinas (Unicamp), professora do Departamento de Sociologia e Ciência Política da Universidade Federal de Santa Catarina (UFSC) e coordenadora do Núcleo de Pesquisa em Movimentos Sociais do Programa de Pós-Graduação em Sociologia e Ciência Política da UFSC.

\section{Referências}

Abers, R., Serafim, L. \& Tatagiba, L. (2014) Repertórios de interação Estado-sociedade em um Estado heterogêneo: a experiência na Era Lula. Dados, 57, pp.325 -357. DOI: 10.1590/0011-5258201411

Almeida, D. (2017) Os desafios da efetividade e o estatuto jurídico da participação: a Política Nacional de Participação Social. Sociedade e Estado, 32(3), pp.649-679. DOI: 10.1590/s0102-69922017.3203005

Almeida, C. \& Tatagiba, L. (2012) Os conselhos gestores sob o crivo da política: balanços e perspectivas. Serviço Social \& Sociedade, s/v(109), pp.68-92. DOI: 10.1590/S0101-66282012000100005

Alves Júnior, M.N. (2002) A contribuição estratégica das ouvidorias para a melhoria dos serviços prestados pelas organizações: um estudo de caso na secretaria de estado da saúde de Santa Catarina. Dissertação de Mestrado. Florianópolis: Universidade do Estado de Santa Catarina.

Capella, A.C. \& Brasil, F.G. (2015) Análise de políticas públicas: uma revisão da literatura sobre o papel dos subsistemas, comunidades e redes. Novos estudos - CEBRAP, s/v(101), pp.57-76. DOI: 10.1590/S0101-33002015000100003

Carlos, E., Dowbor., M. \& Albuquerque, M. (2017) Movimentos sociais e seus efeitos nas políticas públicas. Balanço do debate e proposições analíticas. Civitas - Revista de Ciências Sociais, 17(2), pp.360-378. DOI: 10.15448/1984-7289.2017.2.25925

Cavalcante, P. \& Camoes, M. (2015) Gestão pública no Brasil: as inovações configuram um novo modelo? In: XX Congreso Internacional Del Clad. Lima.

Comparato, B. (2016) Ouvidorias públicas como instrumentos para o fortalecimento da democracia participativa e para a valorização da cidadania. In: R.A. Menezes \& A. S. R. Cardoso (orgs) Ouvidoria pública brasileira: reflexões, avanços e desafios. Brasília: $\quad$ Ipea, pp.43-53. Disponível em: $<$ https://www.ipea.gov.br/portal/images/stories/PDFs/livros/livros/160525_livro_ouvidoria_capitulo_02.pdf>. Acesso em: 7 de set. 2020 .

Corrêa, S. (2012) Um estudo sobre as interfaces entre os Conselhos Municipais de Assistência Social, Educação e Conselho de Direitos da Criança e do Adolescente de Florianópolis. Dissertação de Mestrado. Florianópolis: Universidade Federal de Santa Catarina.

Cortes, S.M.V. (2015) Policy community defensora de direitos e a transformação do Conselho Nacional de Assistência Social. Sociologias, 17(38), pp.122-154. DOI: 10.1590/15174522-017003806

Cortes, S.M.V. (2016) Democratic governance in Brazil: policy communities shaping national councils of social policies. Sociologies in Dialogue, 2(2), pp.225-239.

Cruz-Rubio, C.N. (2015) ¿Qué es (y que no es) gobierno abierto? Una discusión conceptual. Eunomía. Revista en Cultura de la Legalidad, 8, pp.37-53.

Dahlberg, L. (2011) Re-constructing digital democracy: An outline of four positions. New Media \& Society, 13(6), pp.855-872. DOI: $10.1177 / 1461444810389569$

Dryzek, J. (2010) Foundations and Frontiers of Deliberative Governance. New York: Oxford University Press.

Evans, P., Rueschmeyer, D. \& Skocpol, Y. (1985) Bringing the State Back In. Cambridge: Cambridge Press.

Faria, C.F., Silva, V.P. \& Lins, I.L. (2012) Conferências de políticas públicas: um sistema integrado de participação e deliberação? Revista Brasileira de Ciência Política, s/v(7), pp.249-284. DOI: 10.1590/S0103-33522012000100011

Faria, C.F. (2017) Sistema deliberativo, formas de conexão e inclusão política: alcance teórico e prático. Revista Brasileira de Ciências Sociais, 32(95), pp.1-15. DOI: 10.17666/329502/2017 
Frey, K. (2000) Políticas públicas: um debate conceitual e reflexões referentes à prática da análise de políticas públicas no brasil. Planejamento e Políticas Públicas - PPP, s/v(21), pp.211-260.

Fung, A. (2015) Putting the Public Back into Governance: The Challenges of Citizen Participation and its Future. Public Administration Review, 75(4), pp. 513-522. DOI: 10.1111/puar.12361

Gomes, W. (2005) A democracia digital e o problema da participação civil na decisão política. Revista Fronteiras: estudos midiáticos, 7(3), pp.214-222.

Gurza Lavalle, A., Houtzager, P.P. \& Castello, G. (2006) Democracia, pluralização da representação política e sociedade civil. Lua Nova, s/v(67), pp.49-103. DOI: 10.1590/S0102-64452006000200004

Gurza Lavalle, A. \& Isunza Vera, E. (2010) Precisiones conceptuales para el debate contemporáneo sobre la innovación democrática: participación, controles sociales y representación. In: E. Isunza Vera \& A. Gurza Lavalle (orgs) La innovación democrática en América Latina: tramas y nudos de la representación, la participación y el control social. Ciudad de México: Centro de Investigaciones y Estudios Superiores en Antropología Social (CIESAS), pp.19-82.

Gurza Lavalle, A. \& Barone, L. (2015) Conselhos, associações e desigualdade. In: M. Arretche (org). Trajetórias das desigualdades: Quanto o Brasil mudou nos últimos cinquenta anos. São Paulo: Editora Unesp, pp.51-76.

Hendriks, C. (2006) Integrated deliberation: reconciling civil society's dual role in deliberative democracy. Political Studies, 54(3), pp.486-508. DOI: 10.1111/j.1467-9248.2006.00612.x

Hevia, F. \& Isunza Vera, E. (2010) Perspectiva de interfaz aplicada a las relaciones sociedad civil-Estado en México. In: Olvera, A. (org.) La democratización frustrada. Limitaciones institucionales y colonización política de las instituciones garantes de derechos, y participación ciudadana en México. Ciudad de México: Universidad Veracruzana/CIESAS, pp.59-128.

Isunza Vera, E. \& Hevia, F. (2006) Relaciones sociedad civil - Estado en México. Un ensayo de interpretación. Ciudad de México: Centro de Investigaciones y Estudios Superiores en Antropología Social (CIESAS).

Isunza Vera, E. \& Gurza Lavalle, A. (2012) Arquitetura da participação e controles democráticos no Brasil e no México. Novos estudos - CEBRAP, s/v(92), pp.105-121. DOI: 10.1590/S0101-33002012000100007

Klenk, L. \& Prudencio, K. (2016) A comunicação da Prefs: Considerações preliminares sobre o alcance do Facebook como ferramenta de democracia digital. In: S.P. da Silva, R.C. Bragatto \& R.C. Sampaio. Democracia digital, comunicação política e redes. Teoria e prática. Rio de Janeiro: Folio Digital: Letras e Imagem, pp.313-341. Disponível em $<$ http://livro.democraciadigital.org.br/files/2017/05/Democracia-Digital.pdf>. Acesso em 26 de set. de 2020.

Lee, G. \& Kwak, Y. (2011). An Open Government Implementation Model: Moving to Increased Public Engagement. Washington DC: IBM Center for The Business of Government. Disponível em: $<$ http://www.businessofgovernment.org/sites/default/files/An\%20Open\%20Government\%20Implementation\%20Mod el.pdf>. Acesso em: 12 de abr. de 2020.

Levitsky, S. \& Murillo, M.V. (2013) Lessons from Latin America, Building Institutions on Weak Foundations. Journal of Democracy, 24(2), p.93-107.

Lipsky, M. (1980) Street-level Bureaucracy. New York: Russell Sage Foundation.

Long, N. (1999) The Multiple Optic of Interface Analysis. UNESCO Background Paper on Interface Analysis. Paris: UNESCO, $\quad$ pp. 1-25. Disponível em: $<$ http://lanic.utexas.edu/project/etext/llilas/claspo/workingpapers/multipleoptic.pdf>. Acesso em: 7 de set. 2020.

Lüchmann, L.H.H. (2014) 25 anos de Orçamento Participativo: algumas reflexões analíticas. Política \& Sociedade, 13(28), pp.167-197. DOI: 10.5007/2175-7984.2014v13n28p167

Lüchmann, L.H.H., Abrão, R. \& Kieling, M. (2019) Interfaces das interfaces socioestatais. Um estudo sobre as ouvidorias. E-Legis. Revista Eletrônica do Programa de Pós-Graduação da Câmara dos Deputados, 12(28), pp.145-176.

Lüchmann, L.H.H. (2020) Interfaces socioestatais e instituições participativas: dimensões analíticas. Lua Nova, s/v(109), pp.13-49. DOI: 10.1590/0102-013049/109

Lyra, R.P. (2016) Paradigmas de ouvidoria pública e proposta de mudança. In: R.A. Menezes \& A. S. R. Cardoso (orgs) Ouvidoria pública brasileira: reflexões, avanços e desafios. Brasília: Ipea, pp.103-132. Disponível em: $<$ https://www.ipea.gov.br/portal/images/stories/PDFs/livros/livros/160525_livro_ouvidoria_capitulo_05.pdf >. Acesso em 26 de set. de 2020.

Medaglia, R. (2012) eParticipation research: Moving characterization forward (2006-2011) Government Information Quarterly, 29(3), pp.346-360. DOI: 10.1016/j.giq.2012.02.010

Mendonça, R.F. (2016) Mitigating systemic dangers: the role of connectivity inducers in a deliberative system. Critical Policy Studies, 10(2), pp.171-190. DOI: 10.1080/19460171.2016.1165127

Menezes, R.A. \& Cardoso, A.S.R. (2016) Ouvidoria pública brasileira: reflexões, avanços e desafios. Brasília: Ipea. Disponível em: <https://www.ipea.gov.br/portal/index.php?option=com_content\&view=article\&id=27811>. Acesso em: 7 de set. 2020.

Meneses, V. \& Cardoso, D.R. (2018) Participatory Processes in the Contemporary City: What is the Role of Information and Communication Technologies? In: XXII Congresso Internacional da Sociedade Iberoamericana de Gráfica Digital. São Paulo.

Michelli, A. (2016) Redesenhando a Ouvidoria Geral do Estado de SC: uma proposta de reestruturação. Florianópolis: Fundação Escola de Governo.

Migdal, J. Kohli, A. \& Shue, V. (1994) State power and social forces: domination and transformation in the third world. Cambridge: Cambridge University Press. 
Oliveira, V., Lotta, G. \& Cavalcante, P. (2016) Insulamento, autonomia e discricionariedade: atuação da burocracia em contextos democráticos. In: $10^{\circ}$ Encontro da Associação Brasileira de Ciência Política. Belo Horizonte.

Papacharissi, Z. (2002) The Virtual Sphere: The Internet as a Public Sphere. New Media \& Society, 4(1), pp.9-27. DOI: $10.1177 / 14614440222226244$

Pires, R.R.C. \& Vaz, A.C.N. (2014) Para além da participação: interfaces socioestatais no governo federal. Lua Nova, s/v(93), pp.61-91. DOI: 10.1590/S0102-64452014000300004

Pires, R.R.C., 2019. Introdução. In: R.R.C. Pires, (org) Implementando desigualdades: reprodução de desigualdades na implementação de políticas públicas. Rio de Janeiro: IPEA, pp.13-50. Disponível em: $<$ https://www.ipea.gov.br/portal/images/stories/PDFs/livros/livros/190527_livro_implementando_desigualdades_repro ducao_de_desigualdades_Introducao.pdf>. Acesso em: 7 de set. 2020.

Pó, M. V. \& Abrucio, F. (2006) Desenho e funcionamento dos mecanismos de controle e accountability das agências reguladoras brasileiras: semelhanças e diferenças. Revista de Administração Pública, 40(4), pp.679-698. DOI: 10.1590/S0034-76122006000400009

Roberts, B.R. (2001) Las nuevas políticas sociales en América Latina y el desarrollo de ciudadanía: una perspectiva de interfaz. In: Documento elaborado para el Taller Agencia, Conocimiento y Poder: nuevas direcciones. Wageningen. Disponível em: <http://lanic.utexas.edu/project/etext/llilas/claspo/workingpapers/unaperspective.pdf>. Acesso em: 15 de nov. 2019.

Silva, E. \& Ribeiro, A.A. (2016) Sistemas deliberativos em perspectiva meso: a abordagem dos subsistemas aplicada aos conselhos de políticas públicas em Belo Horizonte. Opinião Pública, 22(1), pp.167-194. DOI: 10.1590/1807-01912016221167

Smith, G. (2019) Design Matters: CBNRM and Democratic Innovation. Washington DC: World Bank.

Sorensen, E. \& Torfing, J. (2007) Theoretical Approaches to Governance Network Dynamics. In: E. Sorensen \& J. Torfing (eds) Theories of Democratic Network Governance. New York: Palgrave Macmillan.

Spada, P. \& Allegretti, G. (2017) Integrating Multiple Channels of Engagement in Democratic Innovations: Opportunities and Challenges. In: M. Adria \& Y. Mao (eds) Handbook of Research on Citizen Engagement and Public Participation in the Era of New Media. Pensilvânia EUA: IGI Global, pp. 20-37.

Teixeira, A.C.C., Souza, C.H.L. \& Lima, P.P.F. (2012) Arquitetura da Participação no Brasil: uma leitura das representações políticas em espaços participativos nacionais. Texto para Discussão, s/v (1735). Brasília: IPEA, pp.1-44. Disponível em: $<$ https://www.ipea.gov.br/portal/index.php?option=com_content\&view=article\&id=15081>. Acesso em: 7 de set. 2020.

Warren, M. (2012) When, Where and Why Do We Need Deliberation, Voting, and Other Means of Organizing Democracy? A Problem-Based Approach to Democratic Systems. In: APSA 2012 Annual Meeting Paper. New Orleans.

Zurbriggen, C. (2014) Governance a Latin America perspective. Policy and Society, 33(4), pp. 345-360. DOI: 10.1016/j.polsoc.2014.10.004

\section{Artigos e jornais}

Deep Fakes são ameaça no horizonte (entrevista com Aviv Ovadya) (2018). Polígrafo. Lisboa, 19 de novembro. Disponível em: <https://poligrafo.sapo.pt/entrevista/artigos/950>. Acesso em: 10 de mai. 2020.

\section{Outras Fontes}

CGU (2014) Instrução Normativa OGU no 1, de 5 de novembro de 2014. [online] Brasília: Ouvidoria Geral da União. Disponível em: <https://www.gov.br/ouvidorias/pt-br/ouvidorias/legislacao/instrucao-normativa>. Acesso em: 7 de set. 2020.

\section{Glossário de siglas}

CEAS - Conselho Estadual de Assistência Social

CEI - Conselho Estadual do Idoso SC

CEPA - Conselho Estadual da Igualdade Racial

CEPIN - Conselho Estadual dos Povos Indígenas SC

CES-SC - Conselho Estadual de Saúde de Santa Catarina

CGU - Controladoria Geral da União

CMAS - Conselho Municipal de Assistência Social

CMS - Conselho Municipal de Saúde de Florianópolis

COMDEMA - Conselho Municipal de Defesa do Meio Ambiente de Florianópolis 
CONEDE - Conselho Estadual dos Direitos da Pessoa Portadora de Deficiência SC

CONSEMA-SC - Conselho Estadual de Meio Ambiente de Santa Catarina

FEPAS - Fórum Estadual Permanente de Assistência Social

IP - instituições participativas

NGP - Nova Gestão Pública

OP - orçamento participativo

OSCs - Organizações da Sociedade Civil

PMF - Prefeitura Municipal de Florianópolis,

PNPS - Sistema Nacional de Participação Social

SDS - Secretaria de Estado do Desenvolvimento Econômico Sustentável

SEA - Secretaria de Estado da Administração

SUAS - Sistema Único de Assistência Social

Interfaces of Socio-State Interfaces: Ombudsmen, Management Councils and Institutional Facebooks

ABSTRACT Introduction: The work aims to analyze the articulations between three different types of interfaces between State and society: ombudsmen, management councils and government Facebooks. Materials and Methods: The study is based on the mapping of these interfaces in three different areas of public policies: health, social assistance and environment and at two levels of government (Santa Catarina State Government and Florianópolis City Hall). Based on a general mapping of the interfaces identified on the respective pages of the Government Departments, the research included document analysis, interviews, survey of records in Council minutes and government Facebook posts. Results: Taking dimensions as attributions, competences, institutional design, area of public policies and the role of political, bureaucratic and social actors as an analytical base, the research identified important differences in the greater or lesser capacity for dialogue between the three modalities of socio-state interface, with positive highlight for councils in the areas of health and social assistance. Discussion: The research presents an advance in studies on socio-state interfaces, extending, in addition to participatory institutions, the modalities of society's participation in government agencies. Despite the limited scope of the study, especially when considering the complexity and variety of participatory programs and devices within government agencies and structures and local and regional specificities, the article reinforces the importance of expanding, in a relational way, the understanding of this phenomenon.

KEYWORDS: Social-State Interfaces; Participative Institutions; Governance; Management Councils; Governmental Facebooks.

This is an Open Access article distributed under the terms of the Creative Commons Attribution Non-Commercial License which permits unrestricted non-commercial use, distribution, and reproduction in any medium provided the original work is properly cited.

A produção desse manuscrito foi viabilizada através do patrocínio fornecido pelo Centro Universitário Internacional Uninter à Revista de Sociologia e Política. 